\title{
Identifying strategies early intervention occupational therapists use to teach caregivers.
}

\author{
Jessica L. Colyvas \\ Fox Rehabilitation \\ L Brook Sawyer \\ Thomas Jefferson University \\ Philippa H. Campbell \\ Thomas Jefferson University
}

Follow this and additional works at: https://jdc.jefferson.edu/otfp

Part of the Occupational Therapy Commons

Let us know how access to this document benefits you

\section{Recommended Citation}

Colyvas, Jessica L.; Sawyer, L Brook; and Campbell, Philippa H., "Identifying strategies early intervention occupational therapists use to teach caregivers." (2010). Department of

Occupational Therapy Faculty Papers. Paper 31.

https://jdc.jefferson.edu/otfp/31

This Article is brought to you for free and open access by the Jefferson Digital Commons. The Jefferson Digital Commons is a service of Thomas Jefferson University's Center for Teaching and Learning (CTL). The Commons is a showcase for Jefferson books and journals, peer-reviewed scholarly publications, unique historical collections from the University archives, and teaching tools. The Jefferson Digital Commons allows researchers and interested readers anywhere in the world to learn about and keep up to date with Jefferson scholarship. This article has been accepted for inclusion in Department of Occupational Therapy Faculty Papers by an authorized administrator of the Jefferson Digital Commons. For more information, please contact: JeffersonDigitalCommons@jefferson.edu. 


\title{
Identifying Strategies Early Intervention Occupational Therapists Use to Teach Caregivers
}

\author{
Jessica L. Colyvas, L. Brook Sawyer, Philippa H. Campbell
}

KEY WORDS

- caregivers

- home nursing

- occupational therapy

- teaching
This study investigated early intervention occupational therapists' use of strategies to teach caregivers. A sample of 40 videotapes made by early intervention occupational therapists was randomly selected from an archival videotape data set of provider home visits. The sample included 20 videotapes illustrating traditional services and 20 videotapes illustrating therapists providing participation-based services. Videotapes were rated using the Teaching Caregivers Scale, which rates three variables on 30-s intervals: (1) routine, (2) provider role, and (3) strategies used to teach caregivers during early intervention home visits. Regardless of the model of service, explicit teaching strategies were rarely used during home visits.

Colyvas, J. L., Sawyer, L. B., \& Campbell, P. H. (2010). Identifying strategies early intervention occupational therapists use to teach caregivers. American Journal of Occupational Therapy, 64, 776-785. doi: 10.5014/ajot.2010.09044

n Bronfenbrenner's (1992) ecological perspective of human learning and development, the family is viewed as the most proximal influence on child development. In early intervention, caregivers have significant opportunities to influence their children's development and growth (Bruder, 2000). Services are designed to be congruent with this theory by viewing the entire family, not just the child, as the primary client. The Individuals With Disabilities Education Improvement Act (IDEA) Part C describes a family-centered framework that embraces collaboration between the provider and caregiver and requires early intervention providers to consult with, train, and educate caregivers regarding the special needs of children receiving services (U.S. Department of Education, 1999). The American Occupational Therapy Association (AOTA), as well as the American Speech-Language Hearing Association (ASHA) and the American Physical Therapy Association (APTA), has produced documents and policies supporting family-centered care, recommended practice, and collaboration in the provision of early intervention services (Campbell, Chiarello, Wilcox, \& Milbourne, 2009). Occupational therapists are to assist, empower, teach, and support families when providing early intervention services to facilitate children's development and growth (AOTA, 2004).

\section{Recommended Early Intervention Service Approaches}

The vital role of the family as the teacher of the child and of the provider as the family educator is emphasized in several recognized early intervention approaches (Chai, Zhang, \& Bisberg, 2006; Stremel \& Campbell, 2007). Some of these approaches include routines-based intervention (McWilliam \& Scott, 2001), family-guided routines-based intervention (Cripe, Hanline, \& Dailey, 1997; Woods, Kashinath, \& Goldstein, 2004), activity-based intervention (Pretti-Frontczak \& Bricker, 2004; Valvano, 2004), learning opportunities (e.g., Dunst, 2001; Dunst, Bruder, Trivette, Raab, \& McLean, 2001; Dunst, Hamby, Trivette, Raab, \& Bruder, 2000), and participation-based services (Campbell, 2004; Campbell \& Sawyer, 2007). 


\section{Participation-Based Services}

The participation-based approach differs from routines- or activity-based approaches in that a primary goal is to promote a child's participation in family and community activities and routines. In a participation-based approach, early intervention professionals provide intervention for a child by teaching caregivers how to use two primary types of child interventions to promote their participation and learning: (1) adapting the environment, materials, or the activity/routine, including using assistive technology, and (2) embedding individualized learning strategies within family routines. Participation-based services are differentiated from traditional services in that traditional service models generally are child focused and oriented to children's developmental or physical needs. In traditional services, the provider creates child learning opportunities by working directly with the child to promote functional improvements, and the caregiver may participate as an observer but does not receive specific teaching from the provider.

\section{Traditional Services}

Several studies of early intervention practice have found that providers typically follow a traditional approach, in which they neither facilitate caregiver-child teaching interactions nor incorporate interventions within family activities and routines. Rather, in these studies, providers spent more than half of their time directly teaching the child with the primary role of the caregiver more often reported as an observer (without direct involvement) during interactions between the provider and the child (Campbell \& Sawyer, 2007; McBride \& Peterson, 1997; McWilliam et al., 1998; Peterson, Luze, Eshbaugh, Jeon, \& Kantz, 2007; Wilcox \& Lamorey, 2004).

Peterson and colleagues (2007) also reported that minimal intervention time was focused on facilitating parent-child interactions during early intervention home visits. The researchers used the Home Visit Observation Form to identify interactions, content, and strategies used during home visits and found that parent-child interactions rarely occurred unless another adult (i.e., provider) was included in the interaction. The providers spent more than half of their time solely interacting with the child and less than one third of their time engaged in parent interactions. Even when providers engaged in interactions with families, the provider was the primary initiator of activities and did not facilitate parent-child interaction. Engagement levels of parents varied when different intervention strategies were used. In fact, when providers used strategies that incorporated direct inter- actions (vs. conversation) with the caregiver and child together, engagement levels of mothers considerably increased.

\section{Provider Perspectives on Service Approaches}

Although providers typically do not facilitate caregiver and child interactions, they express attitudes that align generally with the recommended approaches (e.g., BjorckAkesson \& Granlund, 1995; Dunst, Trivette, Humphries, Raab, \& Roper, 2001; King, Law, King, \& Rosenbaum, 1998; Klein \& Chen, 2008; McWilliam, 2000; O’Neil $\&$ Palisano, 2000). In an exploratory study, Klein and Chen (2008) examined self-reports of 118 early intervention providers and found that most perceived themselves as valuing and using activities and strategies described as family-centered practice. Most of the surveyed participants reported highly appreciating strategies for encouraging triadic interactions with the child and caregiver.

In interviews with 31 early intervention providers, participants were asked to describe ideal and typical home visits (Fleming, Sawyer, \& Campbell, in press). When describing ideal visits, most participants described working with and teaching the caregiver. They also described an ideal role of the early intervention provider as one that included using family teaching techniques such as coaching, modeling, providing explanations, and problem solving. Although these providers' descriptions of ideal visits reflected practices associated with participation-based and other service approaches, a low frequency of providing ideal visits was reported. Providers described their role in typical visits as working directly with the child, which is not only consistent with previous research (e.g., Campbell \& Sawyer, 2007; Dunst, Bruder, Trivette, Hamby, et al., 2001) but also characteristic of traditional service practices.

\section{Recommended Practices for Teaching Caregivers}

Most of the recommended early intervention service approaches describe a provider role as a teacher for caregivers. This practice is based on Bronfenbrenner's (1992) theory that families have the most proximal influence on their children's development. Because recommended practices emphasize teaching, it is important to show that caregivers can be taught to use early intervention strategies to influence children's development.

Reports about provider teaching of caregivers or of caregiver learning are limited within any of the early intervention disciplines, including occupational therapy. Woods and colleagues (2004) used a single-case design with four children with autism who were taught 
communication skills by their caregivers within preferred play routines. All children displayed an increase in communication objectives and test scores during intervention when providers taught caregivers to use specific teaching strategies. Generalization to other routines, measured by researcher observation, was limited in three of the four caregiver-child dyads.

In another study, parental strategies to support communication and behavior of their children with developmental disabilities were examined (Hancock, Kaiser, \& Delaney, 2002). The providers successfully taught caregivers strategies that they were able to implement during parentchild interactions with positive changes maintained for $6 \mathrm{mo}$ after intervention. These studies illustrate that caregivers are able to teach their children, but the specific strategies that providers need to use to teach caregivers remain unclear.

Although few studies have examined the effectiveness of caregivers' teaching their children, these studies consistently report that learning strategies are helpful to them in caring for their children. Klein and Chen (2008) examined six mothers' views of early intervention home visiting strategies using the Parent-Focused Interview. Several themes emerged about parents' views of early intervention home visit strategies and activities. When asked what was most helpful to them, the predominant theme was learning specific tasks for working with their children (i.e., "working alongside the home visitor"). Moreover, when asked about what changes or suggestions they had for providers, mothers expressed the importance of parents' involvement in therapy, explanation of interventions, and providing parents with strategies to use between service visits.

In another study, nine mothers were interviewed to identify factors that influenced their learning experiences with therapists (Harrison, Romer, Simon, \& Schultze, 2007). One of the primary themes identified by all mothers, stated broadly, was "learning" (i.e., styles, tools, therapeutic relationship). The predominant method of learning reported by mothers was observing the therapist working directly with the child. A majority of the mothers reported that they "made do" with the model of service their therapists used during treatment. Although observation was the most prevalent method, the mothers stated that it was not as helpful as active involvement. Mothers who did experience active involvement during intervention confirmed the adage attributed to Confucius: "I hear and I forget, I see and I remember, I do and I understand" (as cited in Harrison et al., 2007). By increasing caregiver competence by teaching use of strategies with their children, caregivers will be able to successfully promote their children's engagement in family routines.

Despite the importance of caregivers' learning from early intervention providers, most studies of actual practices suggest that providers more often work directly with the child rather than educate and train the caregiver (e.g., Campbell \& Sawyer, 2007; Dunst, Bruder, Trivette, Raab, et al., 2001; Klein \& Chen, 2008). Only a few studies have explored either the strategies early intervention providers use to teach caregivers or caregiver competence in implementing strategies with their children. Our study represents a first step in better understanding the ways in which occupational therapists teach caregivers during early intervention home visits.

\section{Research Question and Hypothesis}

The purpose of this study was to examine whether occupational therapists who use a participation-based approach differ in their teaching interactions with caregivers from occupational therapists who use a traditional approach. We hypothesized that participation-based occupational therapists would teach caregivers more frequently, because within this service approach, the predominant role of the caregiver is to interact directly with the child and the predominant role of the therapist is to facilitate this interaction. We expected that traditional therapists would teach less often because their primary role is to work directly with the child.

\section{Method}

\section{Sample}

Sample Selection. A sample of 40 videotapes made by occupational therapists in early intervention was randomly selected from an archival videotape data set of early intervention home visits. Multidisciplinary early intervention providers in a large northeastern city were required to take professional development courses to learn about participation-based services and, as part of course completion, to submit a minimum of one 15 - to 20 -min videotape of a provider-selected activity conducted during a service visit with a provider-selected family and child. The archival data set included videotapes submitted by participants from five courses offered during the years from 2003 to 2007.

The goal of the professional development courses was for participants to acquire an initial understanding of participation-based practice and an awareness of how this way of providing services differed from traditional forms of intervention. Participation-based practice was illustrated using videotaped examples showing (1) the role of the 
provider as a teacher and a facilitator of caregiver-child interactions (provider role), (2) the role of the caregiver as directly interacting with the child (caregiver role), and (3) the embedding of interventions into family routines and activities to promote the child's participation and learning (routine).

Videotapes in the archival data set had been rated with the Natural Environments Rating Scale (NERS; Campbell $\&$ Sawyer, 2007), a rating scale that distinguishes between traditional and participation-based practice. The NERS broadly rates eight categories of intervention visits: (1) setting, (2) activity, (3) type of activity, (4) engagement of child, (5) leader of activity, (6) materials, (7) role of caregiver, and (8) role of home visitor. Only the final four categories are scored to obtain an overall rating of traditional or participation-based services by assigning a value of 1 to each characteristic of a participation-based visit. Scores totaling $\leq 2$ points (of 4 points) are scored as traditional, and those with scores of $\geq 2.5$ are labeled as participation based. Each tape was viewed and scored using the NERS by one trained staff researcher or graduate assistant, who watched each videotape in its entirety and then rated each category on the scale. The raters established reliability on the NERS with an agreement rate of $90.4 \%$ for all eight dimensions and $92.4 \%$ for those four dimensions used to determine the specific rating of participation based or traditional services.

From the archival data set, we selected videotapes that (1) were made by occupational therapists and (2) had caregivers present (because no teaching could occur when caregivers were absent), resulting in 59 videotapes. Of the 59 videotapes, 37 were scored as participation based and 22 were scored as traditional. A random sample of 20 participation-based and 20 traditional videotapes was chosen, for a total sample of 40 videotapes.

Provider Characteristics. The selected videotapes consisted of a convenience sample of 31 early intervention occupational therapists. Twenty-two occupational therapists had 1 videotape, and nine had 2 videotapes in the sample, totaling 40 videotapes. Most were female (90.3\%) and White $(77.4 \%)$, although people with other ethnic backgrounds made up $22.6 \%$ of the sample. The mean age of the occupational therapists was $38 \mathrm{yr}$. They had an average of approximately $8.5 \mathrm{yr}$ of experience in their discipline (range $=0.25-30.0 \mathrm{yr}$ ) and $5.8 \mathrm{yr}$ of experience in early intervention (range $=0.33-25.0 \mathrm{yr}$ ). $\chi^{2}$ and independent sample $t$ tests revealed no statistical difference between the participation-based and traditional groups for provider characteristics.

Caregiver and Child Characteristics. Thirty-two caregivers provided demographic information. Most of the children were African-American (40\%) or White (40\%). Hispanic children composed $13.3 \%$ of the sample, and children with other ethnic backgrounds made up $6.7 \%$ of the sample. Slightly more boys (56.0\%) than girls were in the sample. Fifty percent of the children had a diagnosis of developmental delay; the other diagnoses included cerebral palsy, Down syndrome, and Prader-Willi syndrome. Nearly $60 \%$ of the caregivers had completed both high school and additional post-high school education. Slightly more than half $(54.5 \%)$ of the sample children lived in two-parent households. Chi-square analyses revealed no statistical differences in child and family characteristics between the participation-based and traditional groups.

Measure. Each of the 40 videotapes was rated using the Teaching Caregivers Scale, a custom-designed scale that examines the extent to which providers (i.e., occupational therapists, physical therapists, special instructors) teach caregivers. The Teaching Caregiver Scale rates three variables on 30-s intervals: (1) routine, (2) provider role, and (3) teaching strategies. The predominant routine was rated every $30 \mathrm{~s}$ as (1) play, (2) preacademic, (3) caregiving, (4) community/family, or (5) no routine (i.e., no meaningful activity, such as transition time between activities). Provider role was rated every $30 \mathrm{~s}$ as (1) teaching, (2) incidental learning, (3) observing, or (4) not teaching. For an activity to be rated as a teaching strategy, the provider had to teach for a minimum of $10 \mathrm{~s}$ (although it could be nonconsecutive) in the 30-s interval, and the teaching had to be purposeful with explicit feedback, suggestions, or direction given to the caregiver.

The category of incidental learning included interactions among 3 participants (caregiver, child, provider) during a routine in which the provider was not purposefully and explicitly teaching the caregiver. In incidental learning, the provider either worked directly with the child while the caregiver observed (e.g., the caregiver sat on the couch and made small comments on the interaction between the provider and child) or the caregiver, child, and provider jointly interacted with no input from the provider to the caregiver (i.e., both caregiver and provider read a book with the child). Observation was coded when the provider was observing the caregiver, the child, or the caregiver-child interaction in a routine and provided no input to either the caregiver or the child. Not teaching was coded when the provider worked directly with the child while the caregiver was not engaged (i.e., the caregiver was not present or attention was directed to another task such as watching television). The notteaching rating also included intervals with no meaningful activity, such as transition time. 
The final variable of teaching strategies was rated only when the role of the provider was scored as either teaching or incidental learning. For the intervals rated as teaching, the predominant of five teaching strategies was coded in each interval, as follows: (1) conversation and information sharing (i.e., a reciprocal discussion using strategies such as active listening and reflective questioning, with a range of topics including general early intervention issues of service coordination, behavior management, and update since last home visit-not chit-chat), (2) problem-oriented reflection (i.e., a discussion in which problem areas are identified and described, and caregiver and provider jointly consider strategies to improve outcome), (3) direct teaching (i.e., provider is directly working with the child while explicitly describing the intervention to the caregiver; may be a real teaching moment or simulation), (4) caregiver practice with feedback (i.e., caregiver is directly working with the child while the provider gives prompts, suggestions, or encouraging comments to the caregiver), or (5) guided practice (i.e., provider first directly interacts with the child while explicitly teaching the caregiver, and then the caregiver works with the child with provider feedback; multiple turns between caregiver and provider may occur).

Conversation and problem-oriented reflection included discussion-based problem-solving strategies that providers may have used to gather necessary information from caregivers to address concerns, collaborate for current and future planning, or develop opportunities for the child to achieve functional outcomes. These discussion-based strategies were not necessarily embedded within a routine or activity. The remaining teaching strategies (i.e., direct teaching, caregiver practice with feedback, and guided practice) represented child-focused, explicit strategies available to providers as ways of teaching caregivers. For the intervals rated as incidental learning, the predominant of two strategies was coded as follows: (1) modeling (i.e., the provider is primarily working with the child and the caregiver is engaged through observation only) or (2) joint interaction with child (i.e., provider and caregiver are equally interacting with the child, but there is no explicit input to the caregiver from the provider).

Procedure. Each tape was viewed and scored by one trained staff researcher or graduate assistant who watched each videotape in its entirety, rating each of the three variables for each 30-s interval. Before the videotape rating completed for this study, 34 tapes were randomly selected from the 152 multidisciplinary participation-based tapes in the archival data set to establish interrater reliability. An additional 17 tapes were selected throughout the rating process to ensure maintenance of interrater agreement. Using the total of 51 tapes, the raters established an agreement rate of $90 \%$ and between $89 \%$ and $94 \%$ for the three variables (routine $=94 \%$; role of provider $=87 \%$; how the provider teaches $=89 \%$ ).

\section{Results}

Data from all videotapes were summarized for reporting of descriptive information. Simple two-tailed $t$ tests were conducted to compare whether differences emerged between occupational therapists who followed a participation-based service approach and those who followed a traditional service approach for the three variables on the Teaching Caregivers Scale: (1) routine, (2) provider role, and (3) teaching strategies used. In addition, effect size Cohen's $d$ values were computed on the basis of $t$ values, as described in Rosenthal and Rosnow (1991), where $d s$ of $0.20,0.50$, and 0.80 are considered small, medium, and large effect sizes respectively.

\section{Routines}

Figure 1 displays the means for the routines predominantly used during service visits by both participation-based and traditional occupational therapists. Play and caregiving (mostly mealtimes) were the predominant routines, whereas preacademic and community/family routines were rarely the context for the service visit. No statistical difference was found between the routines that participationbased and traditional occupational therapists used as the context for family visits.

\section{Provider Role}

Therapists could be rated on one of four roles per interval: teaching, incidental learning, observing, or not teaching. As depicted in Figure 2, minimal teaching was coded for either participation-based or traditional occupational therapists, and no statistical difference was found between groups for the number of intervals scored as teaching. The provider role for traditional occupational therapists was rated predominantly as incidental learning, whereas participation-based occupational therapists' roles were rated fairly equally as incidental learning and observing. There was statistical significance found between the two groups. Occupational therapists whose videotape was coded as traditional were significantly more likely to engage in incidental learning $(t[38]=3.45, p=.002)$, with a large effect size of 1.12. Participation-based therapists were significantly more likely to engage in observing $(t[38]=-2.99, p=.005)$, with a large effect size of 0.97 . There was little occurrence in either group of not teaching and no statistical significance between the two groups for this category. 


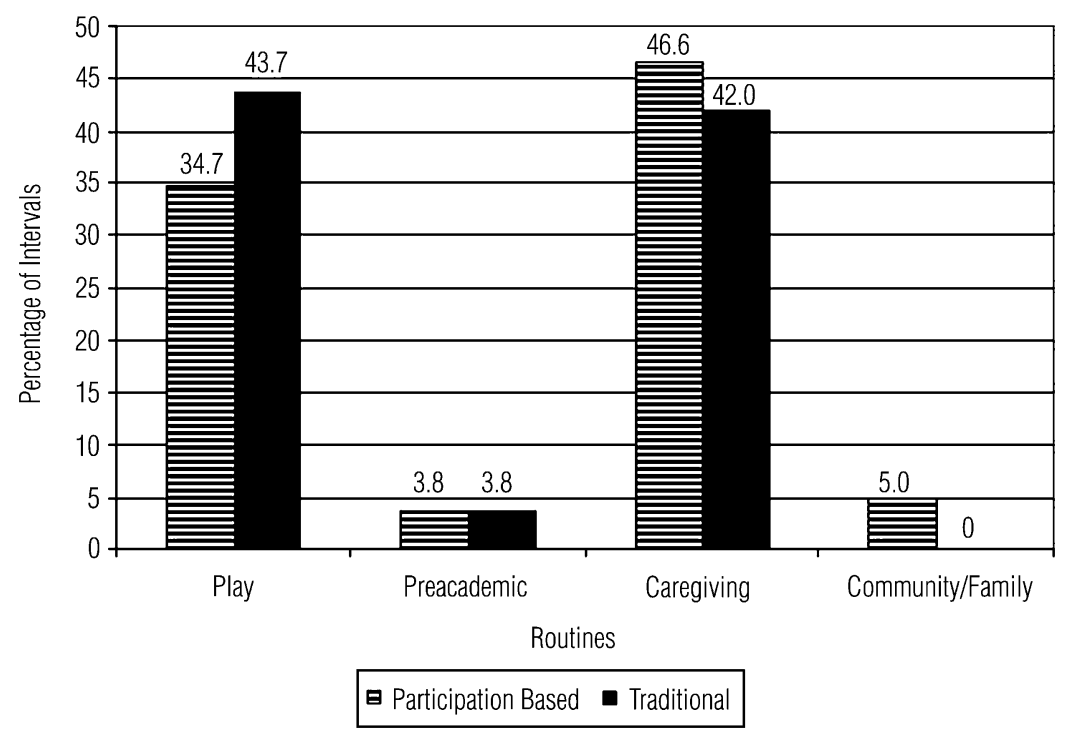

Figure 1. Mean intervals depicting the routines used during participation-based $(n=20)$ and traditional $(n=20)$ videotapes.

\section{Teaching Strategies}

Figure 3 illustrates the intervals during which teaching was rated for each of the five strategies (described earlier). The predominant strategy for both groups was conversation and information sharing. In terms of strategies that directly involved the child (i.e., direct teaching, caregiver practice with feedback, or guided practice), caregiver practice with feedback was used most often for both groups. No statistically significant differences were found between groups for any of these teaching strategies.

As stated previously, incidental learning was used more frequently by occupational therapists who followed a traditional service approach than by those who followed a participation-based approach. We further examined the incidental learning category to identify whether differences emerged in the occurrence of modeling or joint interaction with child. This distinction is particularly important because the caregiver role in these interactions is very different. In modeling, the caregiver is passively engaged (i.e., observing only); in joint interaction with child, the caregiver is actively engaged. The results are illustrated in Figure 4. The traditional group was significantly more likely to model; the participation-based group was significantly more likely to engage in joint interaction with the child. There was statistical significance between the groups for both modeling $(t[38]=6.62, p=.000)$ and joint interaction with child $(t[38]=-5.34, p=.000)$. The effect sizes were large, with $d s=2.15$ and 1.7, respectively.

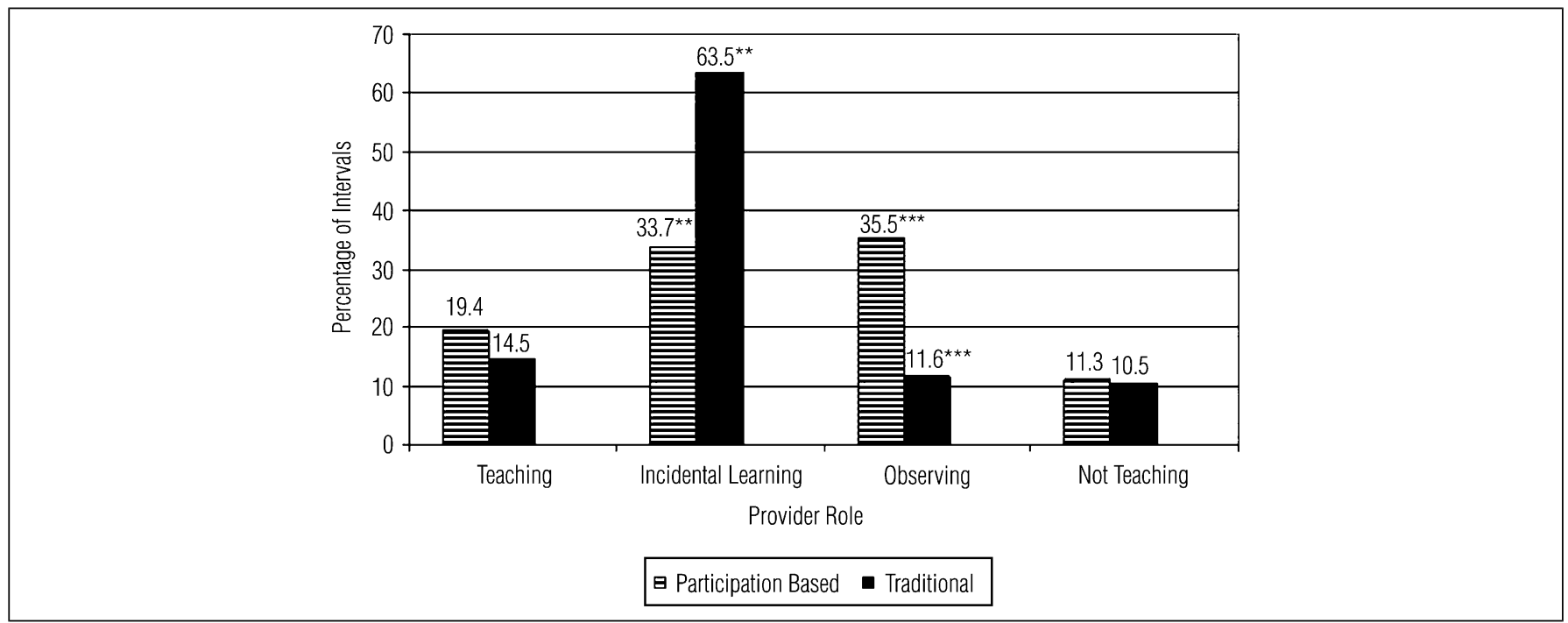

Figure 2. Mean intervals depicting the provider role used during participation-based $(n=20)$ and traditional $(n=20)$ videotapes.

${ }^{* *} p<.01 .{ }^{* * *} p<.001$. 


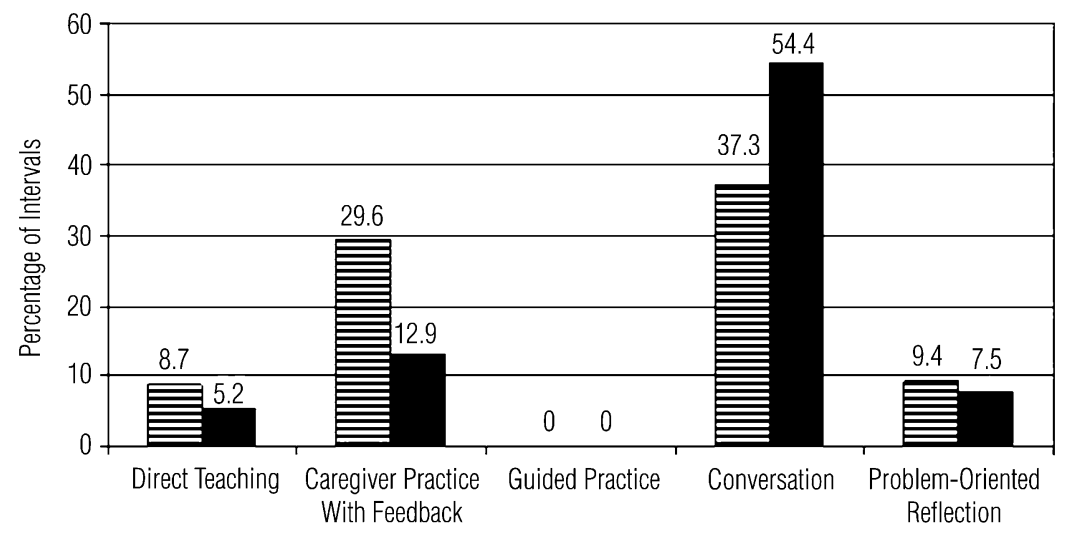

Teaching Strategies

घ Participation Based $\boldsymbol{\bullet}$ Traditional

Figure 3. Mean intervals depicting the teaching strategies used during participation-based $(n=20)$ and traditional $(n=20)$ videotapes.

\section{Discussion}

A primary purpose of early intervention services is to provide support to families so that they may optimize the growth and development of their children. Increasing caregiver competence by teaching caregivers to use strategies with their children is critical. Both the extent to which occupational therapists taught caregivers and the strategies used for teaching were examined in this study for occupational therapists within the categories of traditional and participation-based service. Two important findings emerged. First, little explicit teaching occurred whether occupational therapists used a participation-based or traditional early intervention approach. Occupational therapists in both groups were not likely to explicitly teach caregivers or facilitate their teaching interactions with their children. Second, high amounts of incidental learning strategies were used by both groups. However, traditional occupational therapists were more likely to model strategies by directly working with children while caregivers were passively engaged through observation, whereas participation-based therapists more often used joint interaction with child, a strategy in which the caregiver was actively involved.

\section{Teaching Strategies}

We hypothesized that differences in the degree and the ways in which providers taught caregivers would occur on the basis of the occupational therapist's type of approach (i.e., participation based or traditional) and that participation-based therapists would more frequently use explicit teaching strategies. By contrast, this study illustrated no statistical difference between groups. Less than $20 \%$ of the intervals of participation-based and $<15 \%$ of the intervals of traditional occupational therapists were scored as explicit teaching, illustrating the low use of these strategies by both groups.

The predominant teaching strategy used by both groups was conversation. According to Peterson and colleagues (2007), this method of teaching does not engage the caregiver as much as direct interaction with the child. Conversation, a method to gain and share information about the child, does not necessarily lead to an increase in caregiver competence, involvement, or participation in the intervention process. The explicit strategies that involve both the caregiver and the child (i.e., direct teaching, caregiver practice with feedback, and guided practice) not only support recommended practice but also give caregivers an opportunity to clarify and practice the strategies with occupational therapists before using them on their own with their children between service visits.

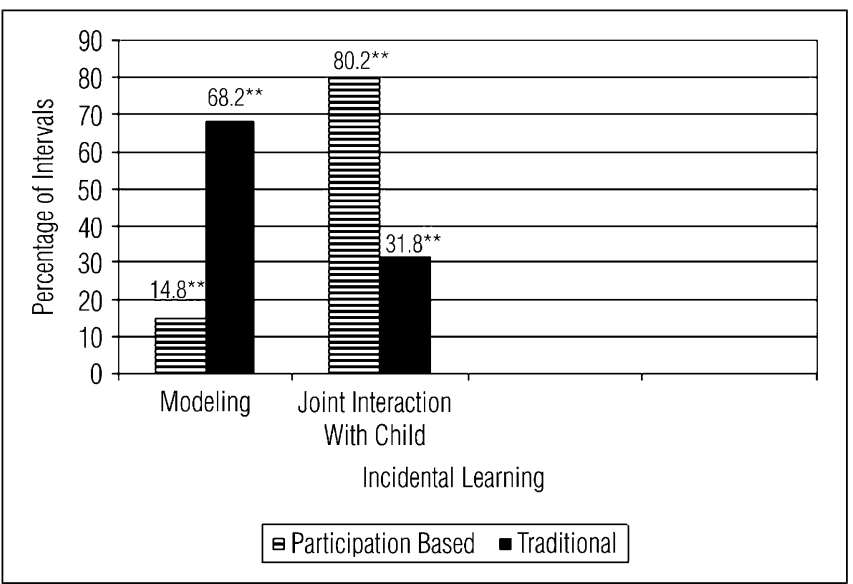

Figure 4. Mean intervals depicting incidental learning used during participation-based $(n=20)$ and traditional $(n=20)$ videotapes. ${ }^{* *} p<.01$. 
Previous research has suggested that although early intervention providers express perspectives aligned with family-centered practice, specifically on the importance of facilitating caregiver-child interactions, their practice is not consistent with their perspectives (e.g., Dunst, Trivette, et al., 2001; Fleming et al., in press; Klein \& Chen, 2008; McWilliam, 2000). Providers, for example, are able to describe participation-based services but readily acknowledge that they are not able to provide them with most families (Fleming et al., in press). Challenges with families (specifically, lack of family involvement) are reported as a primary obstacle to implementing practices such as teaching caregivers (Fleming et al., in press; Klein \& Chen, 2008).

\section{Incidental Learning}

For both service category groups, caregivers, therapists, and children were frequently together in interaction even though no explicit teaching was occurring. Significant differences with large effect sizes existed in the types of incidental learning strategies used by the two groups, however. Participation-based therapists most often used joint interaction with the child, which involved active participation of the caregivers, who more often directly interacted with their child (e.g., the occupational therapist worked with the child over a bolster to facilitate head control while the mother held a toy and engaged the child). Traditional therapists predominantly engaged in modeling, which involved passive engagement of the caregivers, who more often observed the occupational therapist working with the child (e.g., the occupational therapist did hand-over-hand feeding with the child while the mother observed).

Interactions among early intervention providers, caregivers, and children are an important feature of service delivery; however, recommended practice goes beyond simply involving caregivers in the sessions. Caregivers must be explicitly taught to use the strategies being used in the session. Klein and Chen (2008) found that mothers valued being actively involved in services and wanted to be taught to use strategies with their children. Modeling (with caregivers observing) may be a typical way in which caregivers were "taught," but it is not reported by caregivers as engaging (Peterson et al., 2007) or as the most effective method of learning (Harrison et al., 2007). When modeling intervention techniques, the caregiver does not receive explanation from the provider or have an opportunity to work with the child, practice, or receive feedback.

Using joint interaction with the child as a strategy may be an attempt by occupational therapists to actively engage caregivers, but if they are not explicit in their teaching, the caregivers are not given the full opportunity to compre- hend the strategies being used with the children. For example, if the occupational therapist is using a specific handling technique to elicit protective responses but does not explain the demonstration and give the caregiver an opportunity to practice the strategy and receive feedback, the caregiver may feel inadequate to practice between service visits. Moreover, if the caregiver does attempt the strategy, he or she may be guessing as to whether it is being done correctly and safely.

\section{Limitations}

Several limitations should be considered. The videotapes included in this sample were drawn from an archival pool of service videotapes made by multidisciplinary professionals working with caregivers and their children in early intervention. A random sample of 40 (20 traditional; 20 participation-based) videotapes of occupational therapists were drawn from this larger videotape pool to form the convenience sample used in this study. Participants, including these occupational therapists, submitted tapes to meet professional development requirements. They were asked to make a 15- to 20-min videotape of any family or child whom they selected in a typical activity during a home visit but were not specifically instructed to engage or teach caregivers. Had providers been given different instructions (e.g., make a videotape illustrating teaching the caregiver) or if they had videotaped a longer amount of this visit, it is possible that greater amounts of explicit teaching may have been noted.

A second limitation involves the Teaching Caregivers Scale, an interval scale in which the predominant occurrences of each of the three variables were rated in 30-s intervals. In addition, the scale conservatively defined teaching as needing to last 10 (nonconsecutive) s. This definition may have limited the frequency of rated teaching intervals. It is possible that smaller segments of teaching were not captured. Also, guided practice was difficult to rate because if it occurred, it was not contained to a single 30-s interval but was most likely coded as direct teaching in one interval and caregiver practice with feedback in a consecutive interval.

\section{Future Research and Implications for Practice}

This research provides a snapshot of the teaching strategies occupational therapists use with caregivers in early intervention. The results of this study suggest that occupational therapists do not explicitly teach caregivers; rather, therapists in this study relied on modeling or joint interaction with the child as indirect opportunities for caregivers to learn. Using explicit teaching strategies to educate caregivers can empower caregivers to be active 
participants in their child's intervention process and promote their child's development and participation in daily routines and activities. Recommended practices state that occupational therapists should be teaching caregivers (Trivette \& Dunst, 2005), but underpinning this recommendation is the assumption that caregivers are learning. Although learning was not measured in this study, future research in this area should examine the degree to which caregivers are learning to use intervention strategies when specific teaching strategies are used by providers, as well as which strategies are better suited to teaching different interventions.

It is imperative for professional development courses and graduate course work to educate occupational therapists about the strategies available and how to use them effectively, because there may be a lack of effective training models that focus on teaching caregivers as part of family-centered care. The Division of Early Childhood and AOTA serve as great proponents of teaching caregivers, recognizing that the caregiver may have the most influence on a child's development. It is crucial that all early intervention occupational therapists also adopt this position and use recommended practices. If occupational therapists were trained to use explicit teaching strategies, they could feel confident and competent in implementing evidence-based practice while engaging and teaching caregivers.

\section{References}

American Occupational Therapy Association. (2004). Occupational therapy services in early intervention and schoolbased programs. American Journal of Occupational Therapy, 58, 681-685.

Bjorck-Akesson, E., \& Granlund, M. (1995). Family involvement in assessment and intervention: Perceptions of professionals and parents in Sweden. Exceptional Children, $61,520-535$.

Bronfenbrenner, U. (1992). Ecological systems theory. In R. Vasta (Ed.), Six theories of child development: Revised formulations and current issues (pp. 187-248). Philadelphia: Jessica Kingsley.

Bruder, M. B. (2000). Family-centered early intervention: Clarifying our values for the new millennium. Topics in Early Childhood Special Education, 20, 105-115. doi: 10.1177/027112140002000206

Campbell, P. H. (2004). Participation-based services: Promoting children's participation in natural settings. Young Exceptional Children, 8, 20-29. doi:10.1177/ 109625060400800103

Campbell, P. H., Chiarello, L., Wilcox, M. J., \& Milbourne, S. (2009). Preparing therapists as effective practitioners in early intervention. Infants and Young Children, 22, 21-31.

Campbell, P. H., \& Sawyer, L. B. (2007). Supporting learning opportunities in natural settings through participation- based services. Journal of Early Intervention, 29, 287-305. doi:10.1177/105381510702900402

Chai, A. Y., Zhang, C., \& Bisberg, M. (2006). Rethinking natural environment practice: Implications from examining various interpretations and approaches. Early Childhood Education Journal, 34, 203-208. doi:10.1007/s10643-006-0115-x

Cripe, J. W., Hanline, M. F., \& Dailey, S. E. (1997). Family-guided routines for early intervention services. Young Exceptional Children, 1, 18-26. doi:10.1177/ 109625069700100104

Dunst, C. J. (2001). Participation of young children with disabilities in community learning activities. In M. J. Guralnick (Ed.), Early childhood inclusion: Focus on change (pp. 307-333). Baltimore, MD: Brookes.

Dunst, C. J., Bruder, M. B., Trivette, C. M., Hamby, D., Raab, M., \& McLean, M. (2001). Characteristics and consequences of everyday natural learning opportunities. Topics in Early Childhood Special Education, 21, 68-92. doi:10.1177/027112140102100202

Dunst, C. J., Bruder, M. B., Trivette, Raab, M., \& McLean, M. (2001). Natural learning opportunities for infants, toddlers, and preschoolers. Young Exceptional Children, 4, 18-25. doi:10.1177/109625060100400303

Dunst, C. J., Hamby, D., Trivette, C. M., Raab, M., \& Bruder, M. B. (2000). Everyday family and community life and children's naturally occurring learning opportunities. Journal of Early Intervention, 23, 151-164. doi: $10.1177 / 10538151000230030501$

Dunst, C. J., Trivette, C. M., Humphries, T., Raab, M., \& Roper, N. (2001). Contrasting approaches to natural learning environment interventions. Infants and Young Children, 14, 48-63.

Fleming, J., Sawyer, L. B. E., \& Campbell, P. H. (in press). Early intervention providers' perceptions about providing participation-based services. Topics in Early Childhood Special Education.

Hancock, T. B., Kaiser, A. P., \& Delaney, E. M. (2002). Teaching parents of preschoolers at high risk: Strategies to support language and positive behavior. Topics in Early Childhood Special Education, 22, 191-212. doi: $10.1177 / 027112140202200402$

Harrison, C., Romer, T., Simon, M. C., \& Schultze, C. (2007). Factors influencing mothers' learning from pediatric therapists: A qualitative study. Physical and Occupational Therapy in Pediatrics, 27, 77-94.

King, G., Law, M., King, S., \& Rosenbaum, P. (1998). Parents' and service providers' perceptions of the familycenteredness of children's rehabilitation services. Physical and Occupational Therapy in Pediatrics, 18, 21-40.

Klein, D. M., \& Chen, D. (2008). Home visiting practices in early intervention with infants with disabilities: An exploratory study. Early Childhood Services, 2, 207-224.

McBride, S., \& Peterson, C. (1997). Home-based intervention with families of children with disabilities: Who is doing what. Topics in Early Childhood Special Education, 17, 209-233. doi:10.1177/027112149701700206

McWilliam, R. A. (2000). It's only natural ... to have early intervention in the environments where it is needed. Young Exceptional Children Monograph Series, 2, 17-26. 
McWilliam, R. A., Ferguson, A., Harbin, G. L., Porter, P., Munn, D., \& Vandiviere, P. (1998). The family-centeredness of individualized family service plans. Topics in Early Childhood Special Education, 18, 69-82. doi:10.1177/02711214 9801800203

McWilliam, R. A., \& Scott, S. (2001). A support approach to early intervention: A three-part framework. Infants and Young Children, 13, 55-66.

O’Neil, M. E., \& Palisano, R. J. (2000). Attitudes toward family-centered care and clinical decision making in early intervention among physical therapists. Pediatric Physical Therapy, 12, 173-182.

Peterson, C. A., Luze, G. J., Eshbaugh, E. M., Jeon, H., \& Kantz, K. R. (2007). Enhancing parent-child interactions through home visiting: Promising practice or unfulfilled promise. Journal of Early Intervention, 29, 119-140. doi: $10.1177 / 105381510702900205$

Pretti-Frontczak, K., \& Bricker, D. (2004). An activity-based approach to early intervention (3rd ed.). Baltimore, MD: Brookes.

Rosenthal, R., \& Rosnow, R. L. (1991). Essentials of behavioral research: Methods and data analysis (2nd ed.). New York: McGraw-Hill.

Stremel, K., \& Campbell, P. H. (2007). Implementation of early intervention within natural environments. Early Childhood Services, 1, 83-105.
Trivette, C. M., \& Dunst, C. J. (2005). DEC recommended practices: Family-based practices. In S. Sandall, M. L. Hemmeter, B. J. Smith, \& M. E. McLean (Eds.), DEC recommended practices: $A$ comprehensive guide for practical application (pp. 107-111). Missoula, MT: Division for Early Childhood.

U.S. Department of Education. (1999). Part II.: Assistance to states for the education of children with disabilities and the early intervention program for infants and toddlers with disabilities; Final regulations. 64 FR 12406. 34 CFR $\S \S 300,303$.

Valvano, J. (2004). Activity-focused motor interventions for children with neurological conditions. Physical and Occupational Therapy in Pediatrics, 24, 79-107. doi:10.1300/ J006v24n01_04

Wilcox, M. J., \& Lamorey, S. (2004, October 1). Relationshipbased practice in early intervention settings: The experimental investigation of impact and effectiveness: Final report. Washington, DC: U.S. Department of Education, Field-Initiated Research R305T00049.

Woods, J., Kashinath, S., \& Goldstein, H. (2004). Effects of embedding caregiver-implemented teaching strategies in daily routines on children's communication outcomes. Journal of Early Intervention, 26, 175-193. doi:10.1177/ 105381510402600302 